\title{
Developing of Higher Voltage Direct-Current Power-feeding Prototype System
}

\author{
Tadatoshi Babasaki ${ }^{1}$, Toshimitsu Tanaka ${ }^{1}$, Yousuke Nozaki ${ }^{1}$, Toru Tanaka ${ }^{2}$, Tadahito Aoki ${ }^{2}$, Fujio Kurokawa ${ }^{3}$ \\ ${ }^{1}$ NTT Energy and Environment Systems Laboratories \\ ${ }^{2}$ NTT Facilities \\ ${ }^{3}$ Nagasaki University \\ E-mail:babasaki.tadatoshi@lab.ntt.co.jp
}

\begin{abstract}
High efficiency power feeding systems are effective solutions for reducing ICT power consumption of ICT equipment, such as routers and servers, or high efficiency cooling systems. We developed a higher voltage direct current (HVDC) power feeding system prototype. This system is composed of a rectifier, power distribution cabinet, batteries, and ICT equipment. The configuration is similar to a $-48 \mathrm{~V}$ DC power supply system. The output of the rectifier is $100 \mathrm{~kW}$, and the output voltage is $401.4 \mathrm{~V}$. We describe the advantage of an HVDC power feeding system and show that its basic characteristics are stable.
\end{abstract}

\section{INTRODUCTION}

In recent years, the data center market has grown rapidly, and energy saving has become an important issue in the ICT field. A forecast of the Japanese data center market, power consumption, and floorage is shown in Figure 1. Each item is forecast to increase every fiscal year, notably the power consumption for fiscal year 2012 exceeds 10 billion kWh. Increasing the efficiently of power feeding systems for ICT equipment, such as routers and servers, in data centers will hugely affect energy saving as well as reduce the ICT equipment power consumption and increase the efficiency of cooling systems. Conventional $-48 \mathrm{~V}$ direct current (DC) power feeding systems which have been widely used in telecommunications systems, have higher efficiency than alternating current (AC) systems used in data centers in general. Therefore, global discussion on applying DC systems in the data centers has begun.

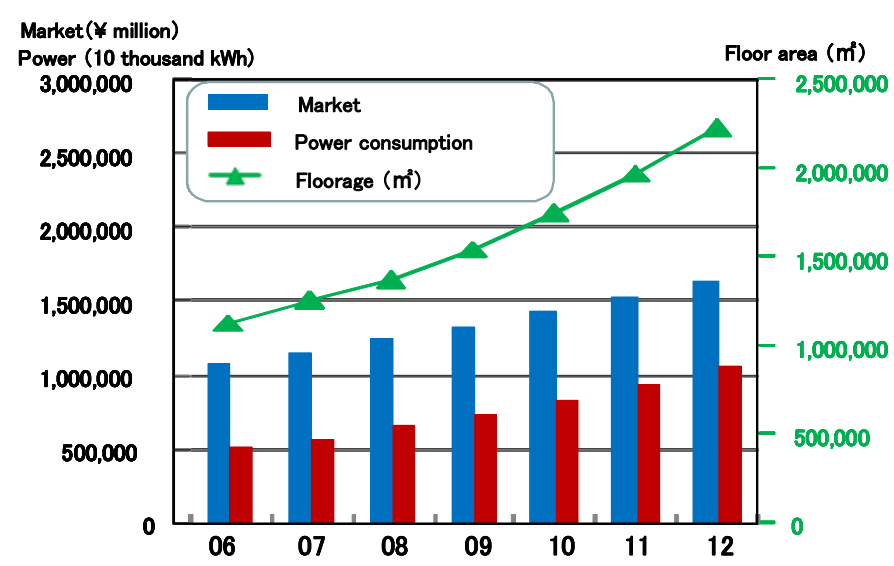

Fig. 1. Data center market, power consumption, floorage
However, power consumption increases as the performance of ICT equipment improves. The power consumption trend of ICT equipment is shown in Figure 2. The power consumption of a $1 \mathrm{U}$ calculation server has more than quadrupled between 2000 and 2006. As a result, the diameters of power cables increase due to large load currents if $-48 \mathrm{~V}$ DC power feeding systems are used, which causes construction and cable space problems. HVDC power feeding systems are expected to solve these problem.

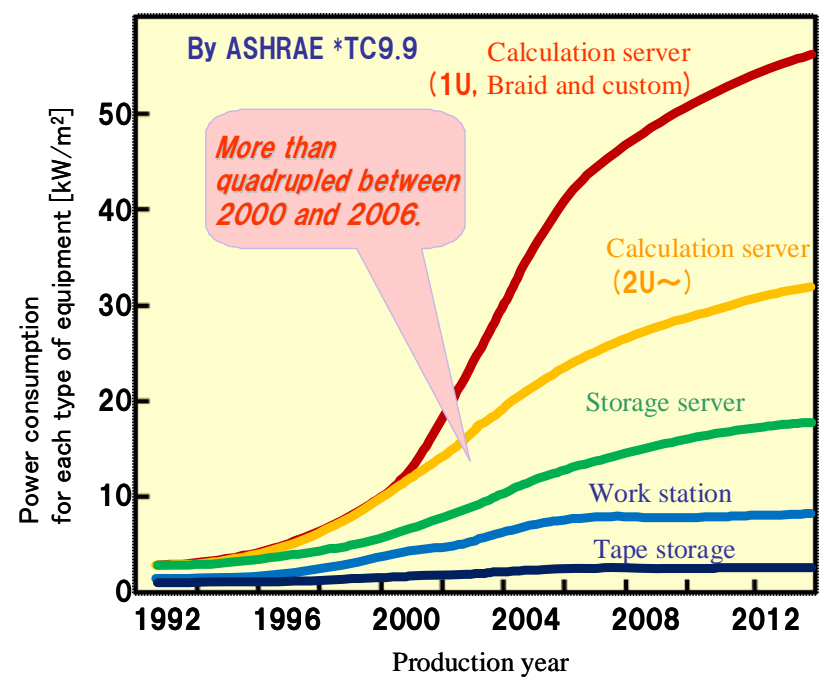

Fig.2 Power consumption of various ICT equipment

\section{ADVANTAGE AND EFFECTS OF HVDC}

The advantage and effects of HVDC are shown in Figure 3. In general, ICT equipment components, such as a CPUs, memory, and hard disks, use DC voltages of 3.3, 5.0 or sometimes 12 or $15 \mathrm{~V}$. Therefore, it is necessary to convert the AC voltage supplied from the power grid into DC voltage in data centers and telecommunication buildings. Moreover, batteries that use DC voltage have to be connected to back-up power. For an AC power system, both AC to DC (AC/DC) and $\mathrm{DC}$ to $\mathrm{AC}$ (DC/AC) conversion are necessary to connect the batteries in uninterruptible power systems (UPSs). AC/DC and DC/DC conversions are also necessary in ICT equipment to supply suitable DC power to the components. As a result, there are four power conversion stages in an AC system. On the other hand in the case of a DC power system, there are only two power conversion stages because power from the 
rectifier and the batteries can be directly supplied to the ICT equipment. In general, the power loss of 1 conversion stage is about $10 \%$ of the total converted power. Therefore, a DC power feeding system is fundamentally more efficient than an AC system due to its fewer power conversion stages. Furthermore, by increase of the DC voltage from the conventional $-48 \mathrm{~V}$ to a higher $400 \mathrm{~V}$, the supply current can be reduced. As a result, system cost and construction flexibility are improved because smaller diameter power cables can be used. An example of power consumption breakdown in an AC power-fed data center is shown in Figure 4. In the graph, the red striped areas indicate the estimated amount of power loss reduction achieved by replacing an AC with an HVDC power feeding system. The HVDC system can reduce the number of DC/AC and AC/DC conversion stages shown in the AC system in Figure 3. It can also reduce the loss caused by the conversion stages and power used for a cooling system for the ICT equipment and power feeding system. The total amount of power loss reduction is estimated to be about $15 \%$.

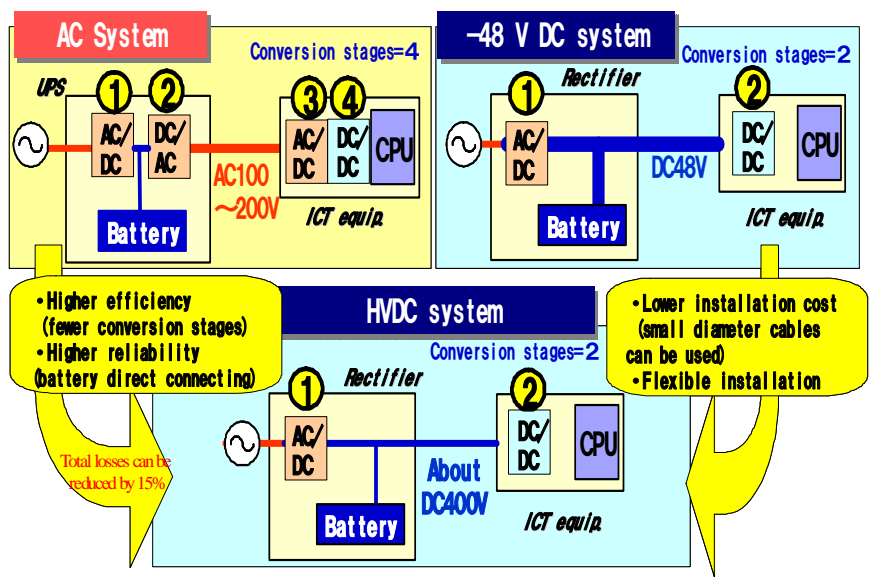

Fig.3 Advantage of HVDC system

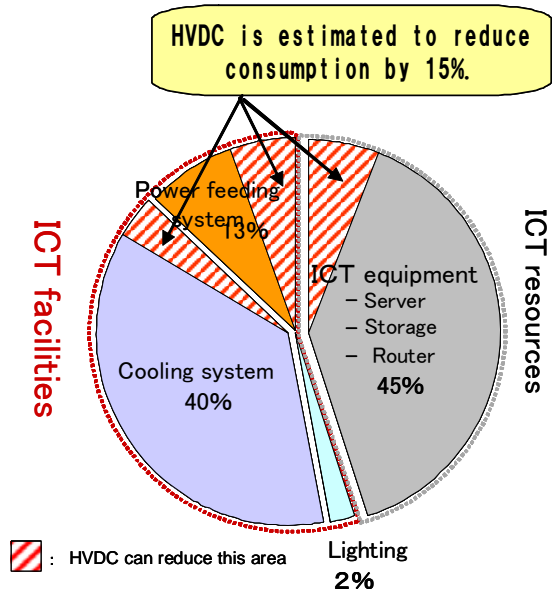

Fig.4 Power consumption break-down of data center

\section{HVDC DEVELOPMENT IN NTT}

\section{A. System configuration and development issues}

Configuration and development issues regarding the HVDC power feeding system being developed through an NTT Energy and Environment Laboratories and NTT Facilities collaboration are shown in Figure 5. The basic configuration is the same as the conventional DC $-48 \mathrm{~V}$ system, for which there have been many technical experiments conducted and knowledge gained ${ }^{[1,2]}$. Efficient development can be achieved by solving the problem caused by changing the feeding power voltage from -48 to $400 \mathrm{~V}$. The HVDC system is composed of a rectifier, batteries, and a power distribution cabinet (PDC). Usually a rectifier rectifies the AC power to DC $400 \mathrm{~V}$ and supplies the power to the batteries and the PDC. The batteries back-up the load power, and the PDC distributes the power for each piece of ICT equipment, respectively. Capacitors are installed in the PDC that suppress the voltage fluctuation and prevent voltage oscillation in the system. When a power line short circuits due to ICT equipment breakdown, the fuse installed in the PDC blows so as to cut off such power lines immediately, and the effect on other ICT equipment is kept to a minimum. If the power grid fails, the batteries start to discharge with no intermittent discontinuity to back-up the load power. The development issues in achieving higher voltage power feeding are related to a higher output voltage rectifier, higher voltage-type PDC, and optimized power feeding design, including user safety.

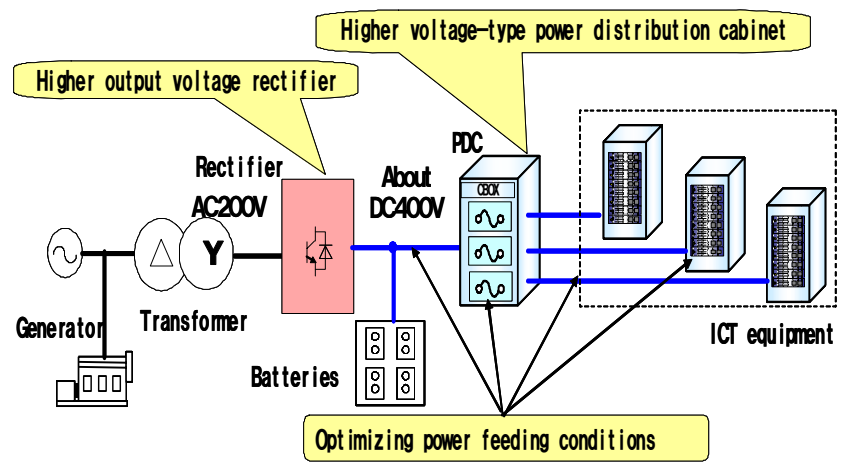

Fig.5 Configuration and development issues for HVDC system

\section{B. Prototype of HVDC power feeding system}

We developed the first prototype in December 2008 and began to evaluate the system. A photograph of the system exterior and the specifications of the prototype system are shown and listed in Figure 6 and Table 1, respectively. The system components, such as the rectifier, PDC, and ICT equipment, are mounted on a 2-meter high, 19-inch rack, and the batteries are installed in another room. The prototype rectifier that NTT Facilities is in charge of developing outputs rated power of $100 \mathrm{~kW}$ with a redundant configuration with nine $(8+1)$ units, each with rated power of $13 \mathrm{~kW}$. The output voltage is set at $401.4 \mathrm{~V}$, which is adjustable to about $360 \mathrm{~V}$. Measured rectifier conversion 
efficiency reaches $95 \%$ with $80 \mathrm{~kW}$ of output power. We will attempt to improve the conversion efficiency further by optimizing the conversion circuit in the future. The prototype system assumes a load of $100 \mathrm{~kW}$ is backed-up for 30 minutes or more. For this, 180 lead battery cells of 200 $\mathrm{Ah}$ are connected in series in the system.

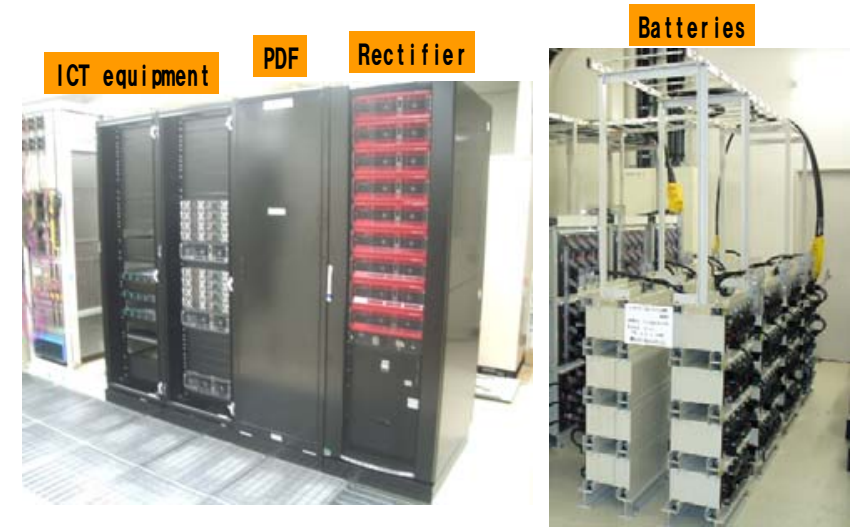

Fig.6 Exterior of our HVDC system

Table 1 Specifications of prototype HVDC system

\begin{tabular}{|c|c|c|c|}
\hline & & Unit & Spec. \\
\hline \multirow{4}{*}{ Rectifier } & Rated output power & $\mathrm{kW}$ & 100 \\
\cline { 2 - 4 } & Number of RF units & - & 9 \\
\cline { 2 - 4 } & AC input voltage & $\mathrm{V}$ & 200 \\
\cline { 2 - 4 } & DC output power & $\mathrm{V}$ & 401.4 \\
\cline { 2 - 4 } & Rated output current & $\mathrm{A}$ & $33 \times(\mathrm{N}-1)$ \\
\hline \multirow{4}{*}{ Battery } & Number of cells & - & 180 \\
\cline { 2 - 4 } & Floating voltage & $\mathrm{V}$ & 2.23 \\
\hline \multirow{5}{*}{ Others } & $\begin{array}{c}\text { Cable } \\
\text { (rectifier-PDC) }\end{array}$ & $\mathrm{mm}^{2}$ & 200 or 325 \\
\cline { 2 - 4 } & $\begin{array}{c}\text { Cable } \\
\text { (PDC-ICT equip.) }\end{array}$ & $\mathrm{mm}^{2}$ & 14 \\
\cline { 2 - 4 } & Grounding & - & $\begin{array}{c}\text { minus } \\
\text { grounding }\end{array}$ \\
\hline
\end{tabular}

\section{Power distribution cabinet}

The power distribution cabinet contains fuses that are installed for every ICT load line, capacitor, and output connection terminal. It is necessary to optimize the circuit conditions such as length and diameter of the power cables, input capacitance of the ICT equipment, and PDC impedance, to achieve a highly reliable power feeding system. We evaluated it through an experimental approach and computer simulation ${ }^{[3]}$. The equivalent circuit and an example of a system study when the ICT equipment causes short-circuit failure are shown in Figure 7. The rectifier, PDC, and cable impedance are modeled as the equivalent circuit, and the Simulation Program with Integrated Circuit Emphasis (SPICE) is used for analysis. The voltage rapidly varies when the resonant voltage is generated between the capacitance and inductance in the system, or the fuse blows short circuiting the ICT equipment. Because the feeding power voltage deviates from the voltage range in which the ICT equipment can operate, stoppage or breakdown of the equipment are forecast. To prevent such voltage fluctuation, it is effective to increase the capacitance of the ICT equipment or decrease the inductance in the capacitor box as much as possible. In the near future, we will optimize these conditions and highly efficient and reliable HVDC will be achieved.

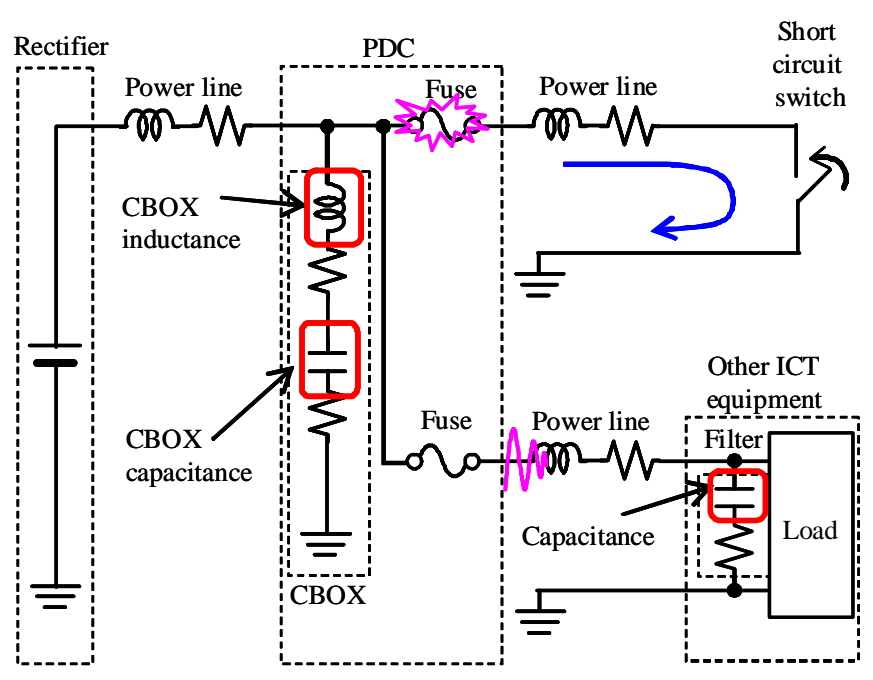

Fig.7 Equivalent circuit for HVDC system

\section{Connector and plugs}

The voltage level of an HVDC system is higher than that of a conventional AC power feed, so it is necessary to consider user safety. A safety connector plug needs to be developed because an arc charge is generated if the point of contact is cut off with the flow of the electronic current in a DC power feed. A connector plug developed by NTT Facilities for a power supply of DC $400 \mathrm{~V}$ is shown in Figure 8. This plug protects people from high voltage and arc discharges. It has a mechanical lock function, i.e., a slide switch that prevents the plug being pulled out during power feeding, and power feeding will not start when the switch is off. Safety can be secured without inconvenience.

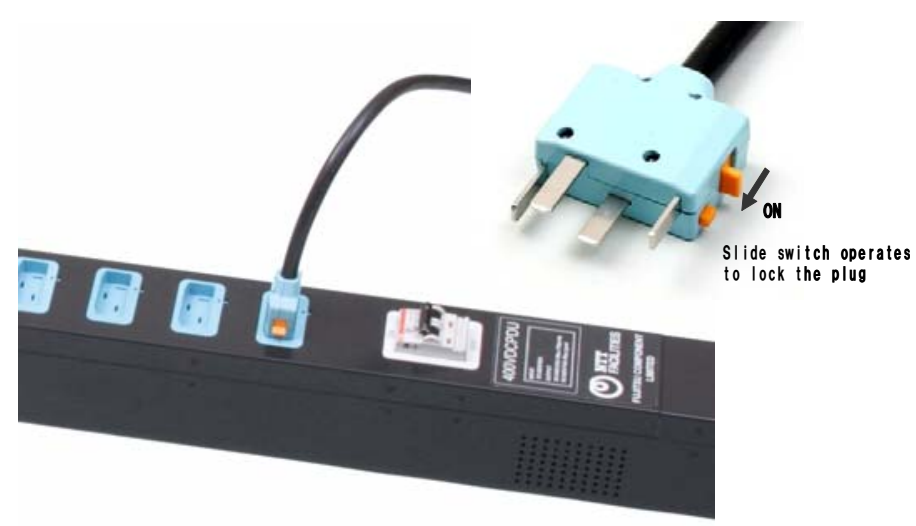

Fig. 8 Connector plug for DC400-V power supply 


\section{EXPERIMENTAL RESULT}

We examined our prototype of an HVDC power supply system. The experimental configuration is shown in Figure 9. The experimental results are shown in Figure 10. Figure 10 shows the results form the load change test and Figure 11 shows the results from the commercial source shutdown test. The capacity of the load is $1 \mathrm{~kW}$, and we can increase the load to $4 \mathrm{~kW}$. The system characteristics was stable when the load increased in the load change test. Commercial shutdown was simulated by breaking a circuit breaker at the input of the rectifier. The operating voltage decreased from 401 to $374 \mathrm{~V}$ because it changed from the output of the rectifier to that of the batteries. The input current at the loads increased because the operating voltage decreased.

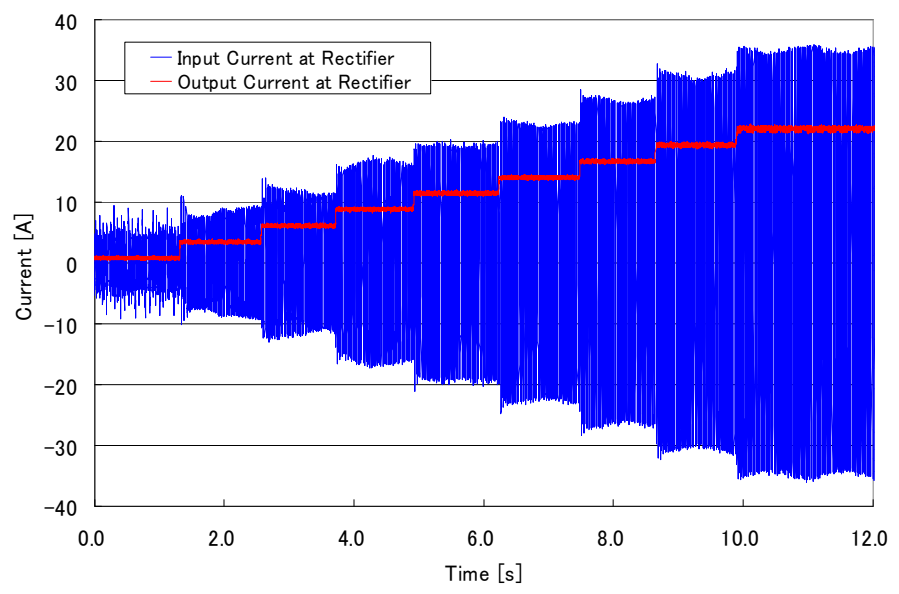

(a) Current at rectifier

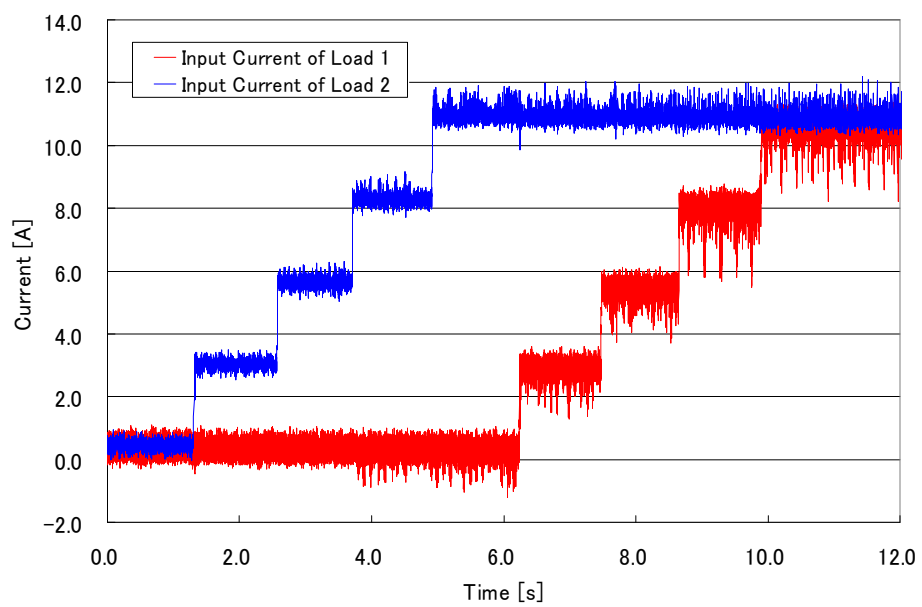

(b) Current at Load

Fig.10 Load change test

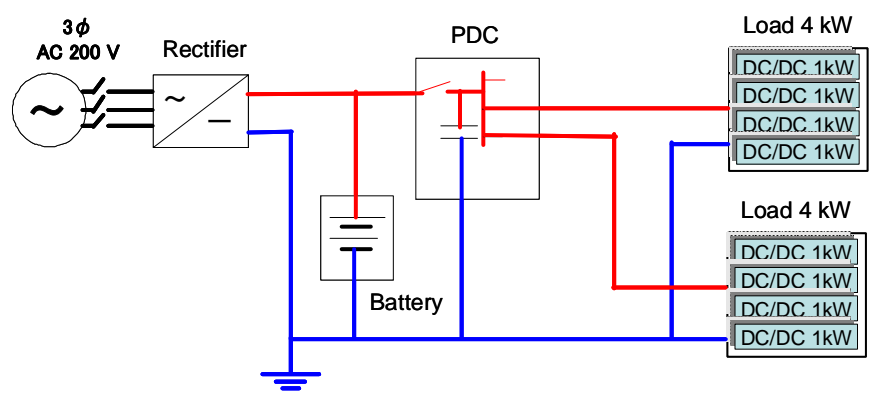

Fig. 9 Experimental Configuration

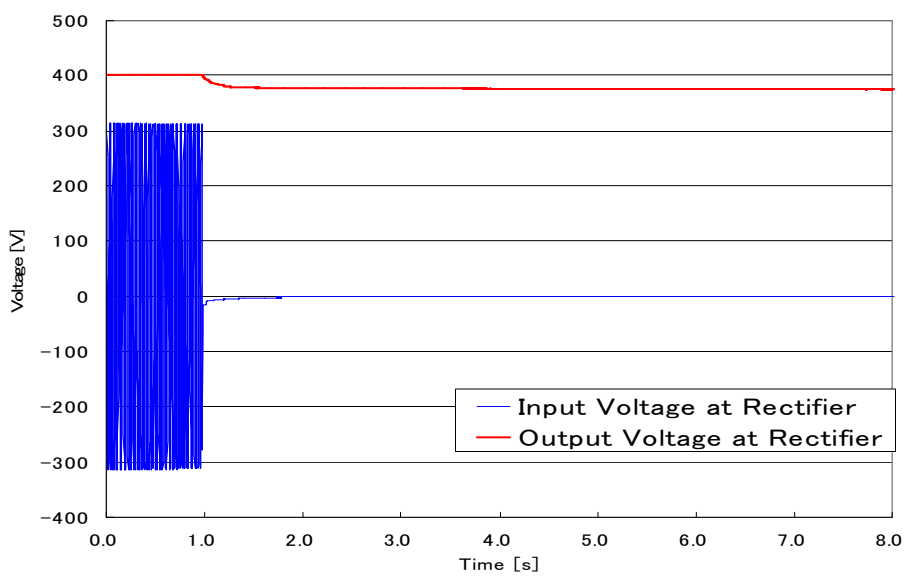

(a) Voltage at rectifier

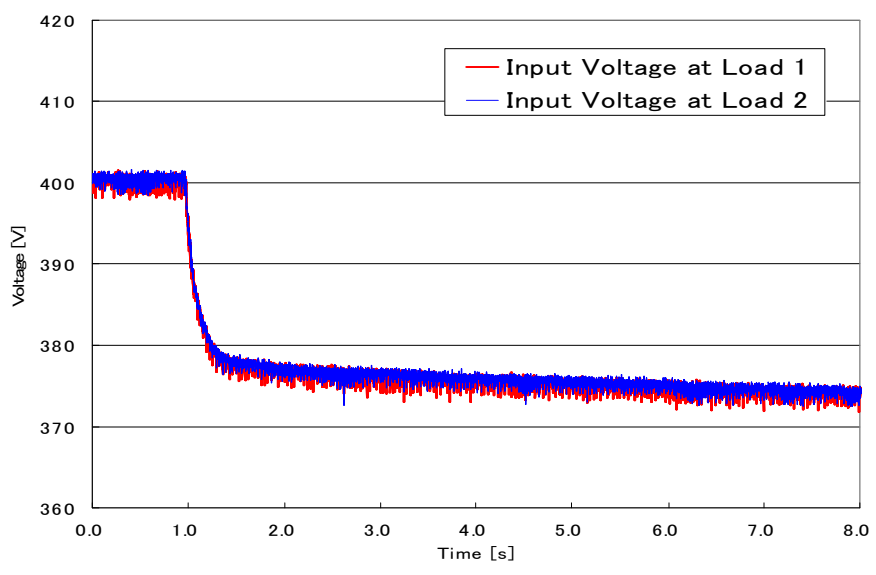

(b) voltage at load

Fig.11 Commercial shutdown test 


\section{CONCLUSION}

We described the advantage of an HVDC power feeding system and the configuration of a prototype system, and showed that its basic characteristics are stable. We will introduce the HVDC system into use after the final prototype system is evaluated. Also, the operating voltage and grounding method has not been determined yet. We will determine them after further discussions.

\section{REFERENCES}

[1] T. Aoki, M. Yamasaki, T. Takeda, and T. Tanaka, "Guidelines for power-supply Systems for Datacom Equipment in NTT", Intelec'02, pp. 134-139, 2002.

[2] T. Babasaki, T. Tanaka, T. Tanaka, "Development of $-48-\mathrm{V}$ DC power supply system for high power ICT equipment”, Telescom2009, 2009.

[3] T. Tanaka, M. Mino, "Fuse blowing Characteristics for HVDC power Supply Systems”, Intelec’08, pp. 535-540, 2008. 